\title{
Cinema and personality disorders
}

\begin{abstract}
Cinema constitutes an audiovisual mean, that represent facts and situations, in order to entertain, inform and teach. No other art form pervades the consciousness of the individual to the same extent and with such power as cinema. Many consider movies to be the most influential form of mass communication (Cape, 2003). The potential of teaching through cinema and movies is its nature and structure, which is linked to pleasure and entertainment. Thus, cinema is a really useful tool to whoever aims in teaching. More precisely, there is a variety of movies that represent many aspects of psychopathology and could be a part of the teaching process on mental health issues. Movies combine realism with imagination and include a lot of information in short timeframes. The use of movies for educational purposes helps and strengthens learning by keeping the interest of learners high and giving them a motivation to learn. Experiential learning is an alternative way of education that extends beyond the classroom, specific textbooks and frontal teaching.
\end{abstract}

Keywords: cinema, teaching, psychopathology, personality disorders, audiovisual means, experiential learning
Volume 3 Issue 4 - 2015

\section{Chrisa Georgopoulou \\ Panteion University, Greece}

Correspondence: Chrisa Georgopoulou, Panteion University, Greece, Tel 6984I29586, Email chrisageo89@gmail.com

Received: March 14, 20I5 | Published: September 16, 2015

\section{Introduction}

Psychopathology and mental disorders have always been very prevalent as content in movies. Movies illustrating characters with mental disorders, like Dr. Dippy's Sanitarium (1906) or Das Kabinett des Dr. Caligari (1919) from Robert Wiener, were released shortly after the Lumiere brothers had invented the cinematographer. While tuberculosis and cancer were popular themes in movies in the past, mental illness is frequently used as a metaphor nowadays. It should not be taken lightly that every movie could be a good illustration of psychopathology. Every scene and line are the results of the directors' meticulous calculations of the audiences' reactions and, to a certain extent, reflect our cultural values about mental illness. It takes the hard work of the authors to guide us through an extensive list of movies relevant to mental illness. They also provide useful material for class discussion in a user-friendly structure.

The contribution of movies in medical educationis a relativelynew tool, although Fritz et al., ${ }^{1}$ published articles on the role of seminars using movies inpsychiatrictrainingin 1979. The use of video or entire films to help learners on bio-psycho-social aspects of healthcarereferstoeducationthroughfilm. ${ }^{2}$ In this point we should mention the broad range of research and practice worldwide. A big example of the educational importance of movies is the effort of McNeilly et al., ${ }^{3}$ and the University of Nebraska. The university organized two seminars for students, who were studying medicine, about psychotherapeutic techniques, by watching short films and videos, like the series "ER", and discussing about the cases of the "difficult" patients. The results of this effort were tremendous, supporting theimportance ofportraying cases andtrainingstudents to betterdeal with suchrealmedical cases. Wedding et al., ${ }^{4}$ Provide a convincing explanation for the successful use of films that aim at teaching psychopathology, in their book Movies and Mental Illness: Using Films to Understand Psychopathology. The arguments include the wide spread popularity and familiarity with films, the experiential power of film, their relatively low cost, and the absence of confidentiality issues (a film shows a psychiatric disorder that bypasses the ethical issues related tothe discussion of real cases and interviewsof the patients). For Zazulak, the biggest advantage of «cinema education» -a term coined by Alexander, Halland Pettice -is that it allows students to explore their personal responses to situations without clinical responsibility.
In accordance with DSM- $5,{ }^{5}$ personality disorders consist Axis II including mental retardation. There are ten specific personality disorders with particular criteria. Primarily, there should be an enduring pattern of inner experience and behavior, which deflect from the cultural expectations of the person. Furthermore, this enduring pattern is inflexible and pervasive in a wide range of personal and social situations. The enduring pattern leads to clinically significant distress or impairment in social, occupational, or other important areas of functioning. Moreover, the pattern is stable and of long duration, and its onset can be traced back at least to adolescence or early adulthood. The enduring pattern is not better accounted for as a manifestation or consequence of another mental disorder. Last but not least, the enduring pattern is not due to the direct psychological effects of a substance (e.g. a drug abuse, a merdication) or a general medical condition (e.g. head trauma).

The following Table 1 shows the films corresponding to each of the ten personality disorders, accordingly with DSM-5, in which a sum of symptoms of all ten personality disorders is represented.

\section{Conclusion}

To sum up, the meaning of cinema education refers to the use of films or videos in order to help the education of students or not on science, art and culture. The data and surveys proving the utility of audiovisual means and films in teaching medical, mental and other issues are strong. Films can transfer knowledge and experiences and evoke emotions.

Data and research that demonstrate the usefulness of video and films in teaching medical and psychiatric issues are strong. The phenomenon of «cinema education» has shown to be a more effective and, at the same time, pleasant method that helps students understands theory and practice. However, the sum of educational films is not enough to give a complete illustration of all details relating to the teaching method. Moreover, there are some black spots, which if not noticed by the instructor using the particular method, there may be individually or no results. There is the possibility of problems with the law of film copyrights, technical problems, and the transmission of false or irrelevant information on the matter of consideration and discussion, if the instructor is not properly evaluate the films he chooses to show students. 
Table I The films corresponding to each of the ten personality disorders, accordingly with DSM-5, in which a sum of symptoms of all ten personality disorders is represented

\begin{tabular}{lllll}
\hline S.No & Personality Disorder & Film & Year & Directed By \\
\hline I & Paranoid personality disorder & Conspiracy Theory & I997 & Richard Donner \\
\hline 2 & Schizoid personality disorder & The Remains of the Day & I993 & Jameslvory \\
\hline 3 & Schizotypal personality disorder & Taxi Driver & 1976 & Martin Scorsese \\
\hline 4 & Antisocial personality disorder & A Clockwork Orange & I97I & Stanley Kubrick \\
\hline 5 & Borderline personality disorder & Girl Interrupted & I999 & James Mangold \\
\hline 6 & Histrionic personality disorder & Mean Girls & 2004 & MarkWaters \\
\hline 7 & Narcissistic personality disorder & To die for & I995 & Gus Van Sant \\
\hline 8 & Avoidant personality disorder & Zelig & I983 & Woody Allen \\
\hline 9 & Dependent personality disorder & When a man loves a woman & 1994 & Luis Mandoki \\
\hline 10 & Obsessive-compulsive personality disorder & The aviator & 2004 & Martin Scorsese \\
\hline
\end{tabular}

\section{Acknowledgments}

None.

\section{Conflicts of interest}

Author declares there are no conflicts of interest.

\section{Funding}

None.

\section{References}

1. Fritz GK, Poe RO. The role of a cinema seminar in psychiatric education Am J Psychiatry. 1979;136(2):207-210.
2. Alexander M, Pavlov A, Lenahan P. Lights, camera, action: Using film to teach the ACGME competencies. Fam Med. 2007;39(1):20-23.

3. McNeilly DP, Wengel SP. The "ER" seminar: Teaching Psychotherapeutic Techniques to Medical Students. Acad Psychiatry. 2001;25(4):193-200.

4. Wedding D, Boyd MA, Niemiec RM. Movies and Mental Illness: Using Films to Understand Psychopathology. (3rd edn), McGraw-Hill College, New York, USA. 1999.

5. American Psychiatric Association. Diagnostic and statistical manual of mental disorders. (5th edn), Washington DC, USA. 2013. 